\title{
Characterization of TCHQ-induced genotoxicity and mutagenesis using the pSP189 shuttle vector in mammalian cells
}

\author{
Jing Wang ${ }^{\mathrm{a}, *}$, Shouyi $\mathrm{Yu}^{\mathrm{a}}$, Shouhai Jiao ${ }^{\mathrm{a}, \mathrm{b}}$, Xiaowen $\mathrm{Lv}^{\mathrm{c}}$, Min Ma ${ }^{\mathrm{d}}$, Ben-zhan Zhu ${ }^{\mathrm{a}}$, Yuguo $\mathrm{Du}^{\mathrm{a}}$ \\ a State Key Laboratory of Environmental Chemistry and Ecotoxicology, Research Center for Eco-Environmental Sciences, Chinese Academy of Sciences, Beijing 100085, PR China \\ b Shandong Institute of Endocrine and Metabolic Diseases, Shandong Academy of Medical Sciences, Jinan 250062, PR China \\ ${ }^{\mathrm{c}}$ Feed Safety Reference Laboratory of Ministry of Agriculture, Feed Research Institute, Chinese Academy of Agricultural Sciences, Beijing 100081, PR China \\ d Laboratory of Environmental Biotechnology, Research Center for Eco-Environmental Sciences, Chinese Academy of Sciences, Beijing 100085, PR China
}

\section{A R T I C L E I N F O}

\section{Article history:}

Received 6 January 2011

Received in revised form 17 August 2011

Accepted 26 August 2011

Available online 8 September 2011

\section{Keywords:}

TCHQ

Genotoxicity

DNA mutation

pSP189

Shuttle vector

A549 cells

\begin{abstract}
A B S T R A C T
Tetrachlorohydroquinone (TCHQ) is a major toxic metabolite of the widely used wood preservative pentachlorophenol (PCP), and it has also been implicated in PCP genotoxicity. However, the underlying mechanisms of genotoxicity and mutagenesis induced by TCHQ remain unclear. In this study, we examined the genotoxicity of TCHQ by using comet assays to detect DNA breakage and formation of TCHQ-DNA adducts. Then, we further verified the levels of mutagenesis by using the pSP189 shuttle vector in A549 human lung carcinoma cells. We demonstrated that TCHQ causes significant genotoxicity by inducing DNA breakage and forming DNA adducts. Additionally, DNA sequence analysis of the TCHQ-induced mutations revealed that $85.36 \%$ were single base substitutions, $9.76 \%$ were single base insertions, and $4.88 \%$ were large fragment deletions. More than $80 \%$ of the base substitutions occurred at $\mathrm{G}: \mathrm{C}$ base pairs, and the mutations were $G: C$ to $C: G, G: C$ to $T: A$ or $G: C$ to $A: T$ transversions and transitions. The most common types of mutations in A549 cells were G:C to A:T (37.14\%) and A:T to C:G transitions (14.29\%) and $\mathrm{G}: \mathrm{C}$ to $\mathrm{C}: \mathrm{G}(34.29 \%)$ and $\mathrm{G}: \mathrm{C}$ to $\mathrm{T}: \mathrm{A}(11.43 \%)$ transversions. We identified hotspots at nucleotides 129,141 , and 155 in the supF gene of plasmid pSP189. These mutation hotspots accounted for $63 \%$ of all single base substitutions. We conclude that TCHQ induces sequence-specific DNA mutations at high frequencies. Therefore, the safety of using this product would be carefully examined.
\end{abstract}

(c) 2011 Elsevier B.V. All rights reserved.

\section{Introduction}

Pentachlorophenol (PCP) is a major industrial and agricultural biocide that has been used extensively as a wood preservative [1]. PCP has become a ubiquitous environmental pollutant due to its worldwide usage, relative stability and improper disposal [1-3]. PCP has been detected in the bodies of people who are not occupationally exposed to PCP, in addition to workers who manufacture PCP. In these individuals, PCP was detected ubiquitously in both bodily fluids (e.g., urine, serum, milk) and in tissues. Additionally, previous studies demonstrated that PCP is metabolized to tetrachlorohydroquinone (TCHQ) by rodents in vivo [2,4] and by liver enzymes from rats and humans in vitro [4,5]. Although PCP has not shown reactivity towards DNA, both PCP and TCHQ were shown to be tumor promoters in previous studies using a mouse skin model in $\mathrm{CD}-1$ mice $[3,6]$.

\footnotetext{
* Corresponding author. Tel.: +86 10 62923539; fax: +861062923549.

E-mail addresses: avaecn@gmail.com, wangjing@rcees.ac.cn (J. Wang).
}

Tetrachlorohydroquinone (TCHQ) is a major toxic metabolite of PCP and is derived from PCP by oxidization and dechloridation; TCHQ is then further oxidized via tetrachlorosemiquinone radicals (TCSQ ${ }^{\bullet}$ ) to form tetrachloro-1,4-benzoquinone (TCBQ) (Fig. 1). In the presence of oxygen, superoxide radicals can be produced by cycles of autoxidation and reduction between TCHQ and its corresponding semiquinone radical under certain physiological conditions $[7,8]$. Additionally, TCHQ was found to bind DNA to form DNA adducts, which induce single strand breaks in human fibroblasts [7,9] V79 cells [10], Chinese hamster ovary cells [11], and mouse livers [12,13]. TCHQ is also able to induce micronuclei and mutations at the HPRT locus of V79 cells [14] and induce 8hydroxy-2-deoxyguanosine (8-OH-dG) formation in V79 cells and B6C3F1 mice $[12,15]$. At low concentrations, TCHQ reduced colonyforming abilities of human fibroblasts and inhibited cell growth in Chinese hamster ovary cells. $p 53$ protein accumulation, glutathione depletion and cellular transformation were also observed in mice treated with TCHQ [13]. These data indicate that TCHQ might be a cytotoxic and genotoxic metabolite of PCP.

However, the mechanisms of genotoxicity and mutagenesis induced by TCHQ remain unclear. In this study, we examined the 


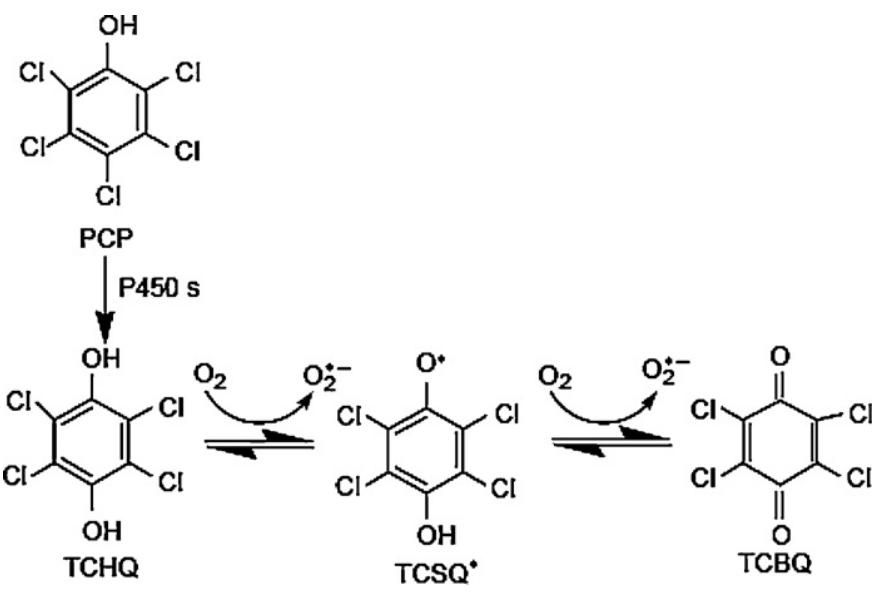

Fig. 1. Diagrams of pentachlorophenol, TCHQ and THCQ metabolites.

genotoxicity of TCHQ by using comet assays to detect DNA breakage and formation of TCHQ-DNA adducts. Then, we further verified the mutagenesis using the pSP189 shuttle vector in A549 human lung carcinoma cells. From our results, TCHQ could significantly induce DNA breakage and formation of DNA adducts. Additionally, DNA sequencing analysis of TCHQ-induced mutations revealed that $85.36 \%$ were single base substitutions, $9.76 \%$ were single base insertions, and $4.88 \%$ were large fragment deletions. More than $80 \%$ of the base substitutions occurred at G:C base pairs, and nucleotides 129,141 and 155 in the supF gene of plasmid pSP189 were identified as hotspots for TCHQ-induced mutations. We conclude that TCHQ induces sequence-specific DNA mutations at high frequencies, which provides a potential mechanism for its mutagenesis. Therefore, the safety of PCP usage should be seriously considered.

\section{Materials and methods}

\subsection{Chemicals and plasmids}

TCHQ $\left(\mathrm{C}_{11} \mathrm{H}_{10} \mathrm{~N}_{4} \mathrm{O}_{4}\right.$, FW 262.23, CAS no. 6804-07-5; 98\%) (Provided by Dr. Ben-zhan Zhu) was primarily purchased from Sigma-Aldrich Company, dissolved in acetone, then diluted in serum- and antibiotic-free medium at the desired concentrations. 5-bromo-4-chloro-3-indolyl- $\beta$-D-galactoside (X-gal) and isopropyl- $\beta$-D-1-thiogalactoside (IPTG) were obtained from Sigma. Dulbecco's MEM cell culture medium (DMEM) was obtained from Invitrogen, and fetal bovine serum (FBS) was obtained from Gibco. The DpnI restriction endonuclease was purchased from New England Biolabs, and the Qiagen PreSpin Plasmid Kit was purchased from Qiagen.

The pGL2 plasmid (Promega, Madison, WI, USA) carries a luciferase gene driven by the simian virus 40 (SV40) promoter and enhancer sequences, resulting in strong luciferase expression in many types of mammalian cells. The pSV- $\beta$-galactosidase plasmid (Promega, Madison, WI, USA) is designed as a positive control vector for monitoring transfection efficiencies of mammalian cells.

The shuttle vector pSP189 [16] and the Escherichia coli strain MBM7070 were kindly provided by Dr. Michael M. Seidman (National Institute on Aging, National Institutes of Health, Baltimore, MD, USA). The pSP189 vector contains the supF mutagenic target, a tyrosine amber-suppressor tRNA gene flanked by the ampicillin gene and the bacterial origin of replication. The vector also carries an SV40 replication origin and large T-antigen gene.

\subsection{Cells and cell culture}

This study employed two types of cells: A549 (ATCC, \#CCL-185) and Vero (ATCC, \#CCL-81) cells. A549 cells were derived from a human lung carcinoma, and Vero cells were initiated from the kidney of a normal adult African green monkey. Both cell lines were provided by the Center for Cell Resources at the Shanghai Institutes for Life Sciences/Cell bank of China Center for Type Culture Collection, Chinese Academy of Sciences (CTCCCAS). A549 and Vero cell lines were routinely cultured in RPMI1640 medium and DMEM medium (Invitrogen, USA) respectively. All media was supplemented with $10 \%$ fetal bovine serum, $100 \mathrm{U} / \mathrm{ml}$ penicillin, and $100 \mathrm{U} / \mathrm{ml}$ streptomycin, and all cultures were maintained at $37^{\circ} \mathrm{C}$ in a humidified mixture of $5 \%$ $\mathrm{CO}_{2}$ and $95 \%$ air.

\subsection{Single cell gel electrophoresis (comet assay)}

The extent of DNA damage caused by TCHQ was determined using the comet assay as described below. After treatment with TCHQ cells were suspended in $1 \%$ low-melting point agarose (LMPA) at a density of $10^{6}$ cells $/ \mathrm{mL}$. The cell suspension was then pipetted onto traditional glass microscope slides that were pre-coated with $0.5 \%$ normal-melting point agarose (NMP). After addition of a third layer of agarose (1\% LMPA), slides were immersed in cold lysing solution $(2.5 \mathrm{M} \mathrm{NaCl}$, $100 \mathrm{mM}$ EDTA, $10 \mathrm{mM}$ Tris, $10 \%$ DMSO, and $1 \%$ Triton X-100 v/v at pH 10). Slides were then placed in a horizontal electrophoresis tank with freshly prepared cold electrophoresis buffer $\left(0.3 \mathrm{M} \mathrm{NaOH}\right.$ and $1 \mathrm{mM}$ EDTA, pH 13) for $30 \mathrm{~min}$ at $4{ }^{\circ} \mathrm{C}$ and subjected to electrophoresis $(20 \mathrm{~V})$ for $15 \mathrm{~min}$. Slides were then washed three times with $0.4 \mathrm{M}$ Tris ( $\mathrm{pH} 7.5$ ) to remove excess running buffer. Afterwards, slides were stained with ethidium bromide $(20 \mu \mathrm{g} / \mathrm{mL})$ and scored by fluorescence microscope with an excitation filter of $515-560 \mathrm{~nm}$ and a barrier filter of $590 \mathrm{~nm}$. DNA damage levels were evaluated according to the head and tail features of the cells.

\subsection{Detection of DNA single-strand breaks (SSB)}

Formation of DNA single-strand breaks was measured by conversion of supercoiled $\Phi \times 174$ DNA into a nicked, open circular form. A standard reaction contained $0.3 \mu \mathrm{g}$ of supercoiled plasmid DNA, $25 \mathrm{mM}$ MOPS or phosphate buffer ( $\mathrm{pH} 7.0$ ) and the indicated concentrations of TCHQ in a total volume of $25 \mu \mathrm{l}$. After incubation at $37^{\circ} \mathrm{C}$ for $60 \mathrm{~min}$, samples were placed on ice and loaded onto $1 \%$ agarose TAE gels. DNA bands were stained with ethidium bromide and analyzed using an Alpha-Innotech FluorChem ${ }^{\mathrm{TM}} \mathrm{FC} 2$ gel screening system.

\subsection{Treatment of DNA with $T C H Q$ in vitro}

$30 \mu \mathrm{g}$ pSP189 DNA or pGL2 DNA were treated with TCHQ at distinct concentrations $(10,25,50,100,200,300$ and $500 \mu \mathrm{M})$ and $0.1 \%$ acetone in $0.5 \mathrm{~mL}$ of TE buffer [10 $\mathrm{mM}$ Tris- $\mathrm{HCl}$ and $1 \mathrm{mM}$ EDTA $(\mathrm{pH} 7.8)]$. The reaction was carried out at $37^{\circ} \mathrm{C}$ for either 0.5 or $1 \mathrm{~h}$ in the dark. After incubation, the plasmids were precipitated by ethanol, filtered through SUPER ${ }^{\mathrm{TM}}-02$ (Takara, Japan) to remove excess TCHQ, and redissolved in TE buffer at a concentration of $0.1 \mu \mathrm{g} / \mu \mathrm{L}$ and stored at $-20^{\circ} \mathrm{C}$. The TCHQ-modified pGL2 plasmid was used for host cell reactivation assays and the TCHQ-modified pSP189 was used for SupF mutagenesis assays.

\subsection{Host cell reactivation assay}

We used a previously described host cell reactivation assay to evaluate DNA damage repair capabilities $[17,18]$. Briefly, TCHQ-modified pGL2 plasmid $(1.8 \mu \mathrm{g})$ (for monitoring repair of TCHQ-DNA adducts) and pSV- $\beta$-galactosidase plasmid $(0.2 \mu \mathrm{g})$ (for monitoring transfection efficiency) were co-transfected into cells (cultured in a $35 \mathrm{~mm}$ dish at a density of $3 \times 10^{5}$ cells/dish) by using Lipofectamine ${ }^{\mathrm{TM}}$ 2000 (Invitrogen, Carlsbad, CA, USA) according to the manufacturer's instructions. The transfection procedure has been previously described in detail [19]. For repair of TCHQ-DNA adducts, transfected cells were incubated for another 8 and $24 \mathrm{~h}$, as indicated. Luciferase and $\beta$-galactosidase activities were determined by the Luciferase Assay System and the $\beta$-galactosidase Enzyme Assay System (Promega, Madison, WI, USA), respectively, according to the provided standard protocols. The DNA repair capability was evaluated by the removal of TCHQ-DNA adducts, which correlates with the recovery of luciferase activity. Relative luciferase activity was defined as [(luciferase activity/ $\beta$-galactosidase activity) in cells transfected with TCHQmodified pGL2/(luciferase activity/ $\beta$-galactosidase activity) in cells transfected with un-modified pGL2] $\times 100 \%$.

\subsection{SupF mutagenesis assay}

The pSP189 shuttle vector carries a supF gene as a mutation target for studying mutagenesis in mammalian cells [16]. The mutagenicity of the TCHQ-modified pSP189 was determined as previously described [20] with some modifications. Briefly, pSP189 (5 $\mu \mathrm{g})$ with or without TCHQ modification was transfected into A549 cells using Lipofectamine ${ }^{\mathrm{TM}} 2000$ (Invitrogen, Carlsbad, CA, USA). After a $48 \mathrm{~h}$ period to allow repair of TCHQ-DNA adducts and replication of plasmids, pSP189 plasmids were rescued from the cells by the Promage Plasmid Purification Kit, and then digested with DpnI (Promage, $20 \mathrm{U}$ ) to remove any parental DNA introduced by transfection.

The recovered plasmid DNA was transformed into E. coli MBM7070 bacteria using the calcium chloride method. E. coli MBM7070 carries an amber-mutated lacZ gene as an indicator of supF compensation from the pSP189 plasmid. Transformed $E$. coli were then assayed for ampicillin resistance and mutations in the supF gene by plating on agar plates containing ampicillin $(100 \mu \mathrm{g} / \mathrm{mL}), \mathrm{X}-\mathrm{gal}(50 \mathrm{mg} / \mathrm{mL})$, and IPTG $(200 \mathrm{mg} / \mathrm{mL})$ and incubating at $37^{\circ} \mathrm{C}$ for $24 \mathrm{~h}$. E. coli carrying plasmids with supF mutations formed white or light blue colonies, whereas $E$. coli carrying plasmids with a functional supF gene formed blue colonies. All colonies were counted and mutation frequencies were calculated. Plasmid DNA samples were extracted and purified from the above white and light blue colonies that were derived from spontaneous or TCHQ-induced mutants, respectively. The resulting DNA sequences of 47 mutants, including six from control groups, were determined using di-deoxy sequencing with 


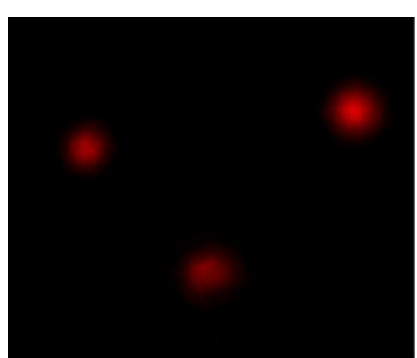

CT

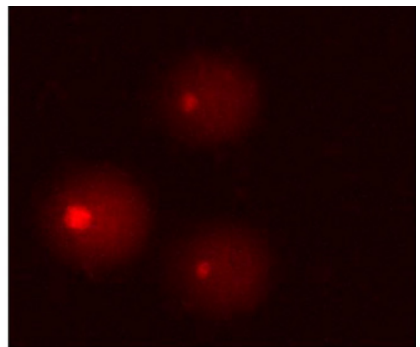

TCHQ $50 \mu \mathrm{M} / 1 \mathrm{~h}$
Fig. 2. TCHQ-induced DNA damage. Photomicrography of Vero cells treated with TCHQ for $1 \mathrm{~h}$ when analyzed with a comet assay.

the 5'-GGCGACACGGAAATGTTGAA-3' primer. All sequenced colonies contained the supF promoter region, including those in which the supF gene had been deleted. pSP189 shuttle vectors containing an 8 base 'signature' were excluded from further analysis. Poisson distribution analysis was used to assess randomness in the mutation spectra. "Hotspots" were assumed when there was a greater than 4 -fold increase in the number of mutations than expected in a random (Poisson) distribution [21].

\section{Results}

\subsection{Genotoxicity of TCHQ and the evaluation of cellular repair of TCHQ-DNA adducts}

DNA damage induced by TCHQ was measured in Vero cells using a comet assay. Extensive TCHQ-induced DNA breakage is shown in Table 1 and Fig. 2. The trihydroxamate iron chelator desferrioxamine (DFO) (1 mM), but not dimethylsulfate (DMSO) $(1 \%, 140 \mathrm{mM})$, that was simultaneously added to the cells significantly prevented DNA damage. Pretreatment with DFO also exerted protective effects. However, the similar significant protection in simultaneous treatment was achieved only at higher DFO concentration ( $5 \mathrm{mM}$ ) in pretreatment. Additionally, higher concentration of DMSO $(5 \%, 700 \mathrm{mM})$ also showed protective effects, although higher concentration and prolonged treatment with DMSO caused more damage. These results with different treatments are similar with previous study [2], and the underlying explanation was demonstrated by the authors.

To verify the potential induction of oxidative DNA damage in TCHQ reactions, we monitored single strand break (SSB) induction using the purified $\Phi \times 174$ plasmid. Incubation of TCHQ with plasmid DNA led to a significant increase in unwinding of supercoiled (intact) plasmid molecules, as evidenced by their slower mobility in agarose gels (Fig. 3A). This slower mobility appeared in a dosedependent manner. However, when the plasmids were pretreated with different concentrations of DFO, SSB induction by TCHQ was significantly inhibited. Treatment with $5 \mathrm{mM}$ DFO could completely protect against DNA strand breakage induced by $200 \mu \mathrm{M}$ of TCHQ (Fig. 3B).

According to previous studies [2], TCHQ readily autoxidizes at physiological $\mathrm{pH}$, producing a TCSQ radical intermediate with a visible absorption peak at $455 \mathrm{~nm}$. With the addition of DFO, a powerful TCSQ radical scavenger, TCHQ autoxidation was markedly enhanced. TCSQ radicals formed immediately and completely decayed with concurrent formation of TCBQ. And during the autoxidation of TCHQ to TCBQ the producing $\mathrm{O}_{2}{ }^{--}$radical could be changed into $\mathrm{H}_{2} \mathrm{O}_{2}$, and producing $\mathrm{OH}$ radicals from the reaction of $\mathrm{H}_{2} \mathrm{O}_{2}$ and TCBQ could do damage to DNAs as demonstrated by Zhu et al. [8,22-24]. Therefore, we also examined the induction of oxidative DNA damage by $\mathrm{H}_{2} \mathrm{O}_{2}$ and TCBQ, a metabolite of the TCHQ autoxidation reaction. As shown in Fig. 3C, DNA strand breakage induced by TCBQ alone is not very significant compared with the control. However, when DNA was administered along with $\mathrm{H}_{2} \mathrm{O}_{2}$ and TCBQ differences in the DNA strand breakage became significant when compared with the control. Mechanisms by which hydroxyl radicals are produced from TCBQ $/ \mathrm{H}_{2} \mathrm{O}_{2}$ have been verified as a metal-independent molecular mechanism [22,23]. During this reaction, TCBQ not TCSQ radical is essential to produce $\mathrm{OH}$.
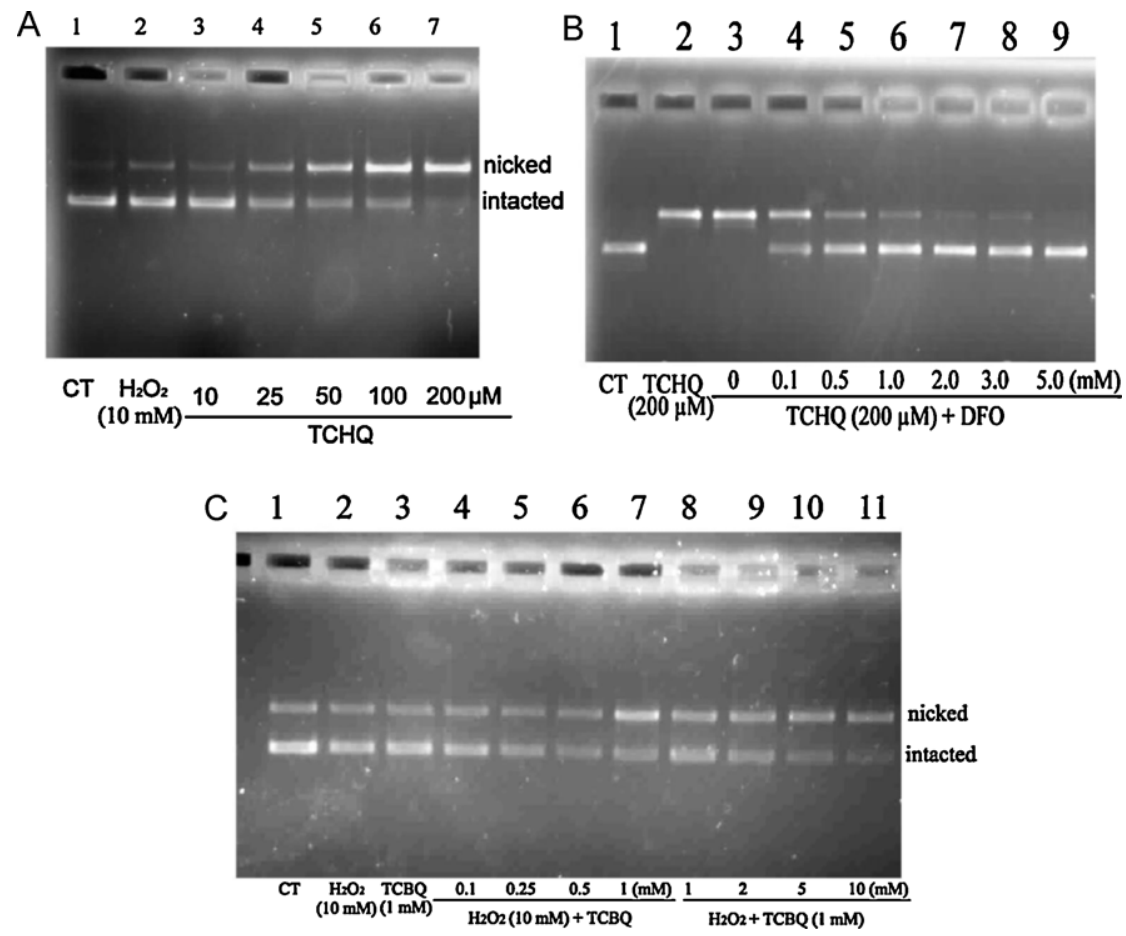

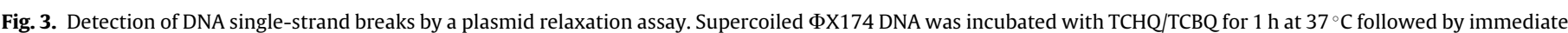

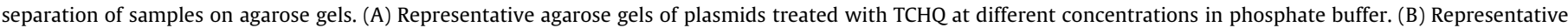

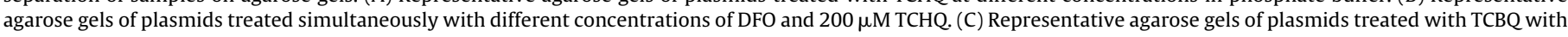
$\mathrm{H}_{2} \mathrm{O}_{2}$. 
Table 1

DNA damage induced by TCHQ and the protective effects of DFO and DMSO in Vero cells as measured in the comet assay.

\begin{tabular}{|c|c|c|c|c|c|}
\hline $\mathrm{TCHQ}(\mu \mathrm{M})$ & Tail moment & Co-treatment (Simultaneously) & Tail moment & Co-treatment (Pretreatment) & Tail moment \\
\hline 0 & $1.8 \pm 0.8$ & TCHQ alone $(10 \mu \mathrm{M})$ & $22.3 \pm 1.2$ & TCHQ alone $(10 \mu \mathrm{M})$ & $22.3 \pm 1.2$ \\
\hline 5 & $11.5 \pm 1.3$ & $\mathrm{DFO}(1 \mathrm{mM})$ & $2.2 \pm 0.3$ & $\mathrm{DFO}(5 \mathrm{mM})$ & $1.8 \pm 0.5$ \\
\hline 10 & $22.3 \pm 1.2$ & DFO/TCHQ & $7.6 \pm 1.2$ & $\mathrm{DFO} / \mathrm{TCHQ}$ & $8.4 \pm 1.3$ \\
\hline 25 & $35.2 \pm 1.8$ & DMSO $(1 \%, 140 \mathrm{mM})$ & $1.8 \pm 0.2$ & $\operatorname{DMSO}(5 \%, 700 \mathrm{mM})$ & $8.7 \pm 1.1$ \\
\hline 50 & $38.2 \pm 2.1$ & DMSO/TCHQ & $21.8 \pm 1.4$ & DMSO/TCHQ & $10.1 \pm 1.2$ \\
\hline $\mathrm{H}_{2} \mathrm{O}_{2}(45 \mu \mathrm{M})$ & $16.6 \pm 1.5$ & & & & \\
\hline
\end{tabular}

radical also explain why DMSO has protective effects mentioned above.

TCHQ-modified pGL2 plasmids carrying a constitutively expressing luciferase gene were transiently transfected into A549 cells. After $8 \mathrm{~h}$ and $24 \mathrm{~h}$ repair periods for cellular repair of TCHQDNA adducts, the luciferase activity in cell extracts was analyzed. As shown in Fig. 4, A549 cells were able to repair TCHQ-DNA adducts. After $18 \mathrm{~h}$ period for DNA repair, the recovered luciferase activity from the 50 or $200 \mu \mathrm{M}$ TCHQ-modified pGL2 plasmids was about $70-90 \%$ or $40-50 \%$ of the un-modified plasmids, respectively. Recovery of luciferase activity by repair of TCHQ-modified pGL2 plasmids was significant. Unable to remove the DNA adducts by DNA repair machineries is important for mutation establishment, so the treatment of plasmid DNA with different concentration of TCHQ was adopted in the following shuttle vector mutagenesis study.

\subsection{High frequency of TCHQ-induced mutations in pSP189}

In this study, we employed the pSP189 shuttle vector mutagenesis system to evaluate TCHQ-induced mutagenesis. The spontaneous mutation frequency of the pSP189 shuttle vector plasmid replicated in A549 cells was very low in this study. Only six spontaneous mutants were obtained from a total of 29,324 colonies screened, giving a mutation frequency of $2.04 \times 10^{-4}$, which is consistent with previous reports [25-27]. In contrast, TCHQ treatment produced 41 plasmid mutations in 10,498 colonies, which gave a calculated mutation frequency of $39.06 \times 10^{-4}$. When the pSP189

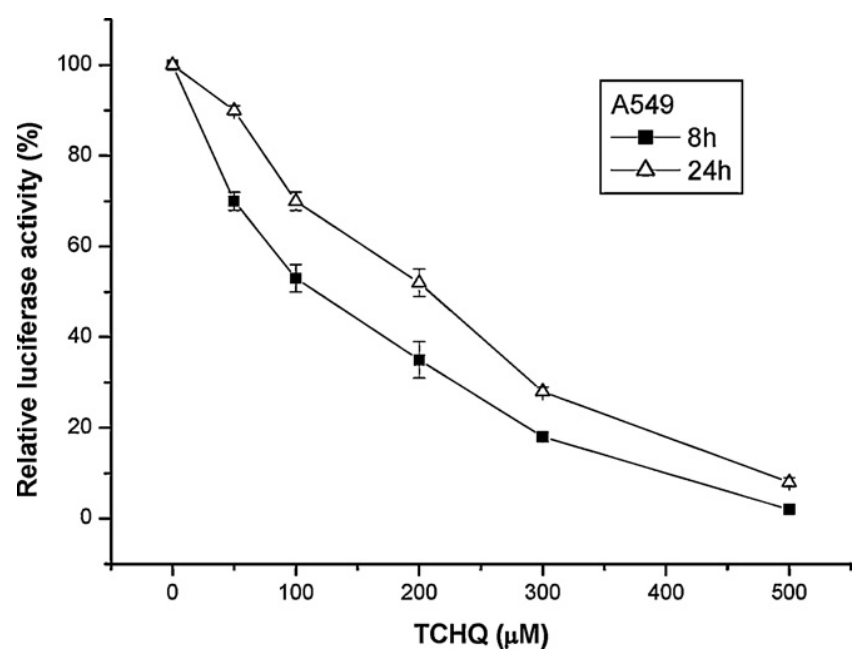

Fig. 4. Evaluations of repair of the TCHQ-DNA adducts by using the host cell reactivation assay. pGL2 plasmid DNA was incubated with various concentrations of TCHQ to allow TCHQ-DNA adduct formation. After purification, TCHQ-modified pGL2 plasmids and pSV- $\beta$-galactosidase plasmids were co-transfected into A549 cells. After transfection for either 8 or $24 \mathrm{~h}$, luciferase activity and $\beta$-galactosidase activity were determined. Repair of the TCHQ-DNA adducts was evaluated by the recovery of luciferase activity between $8 \mathrm{~h}$ and $24 \mathrm{~h}$. Relative luciferase activity was defined as [(luciferase activity/ $\beta$-galactosidase activity) in cells transfected with TCHQmodified pGL2/(luciferase activity/ $\beta$-galactosidase activity) in cells transfected with un-modified $\mathrm{pGL} 2] \times 100 \%$. The data are presented as mean $\pm \mathrm{SD}, n \geq 3$. plasmid was treated with 10,25 and $50 \mu \mathrm{mol} / \mathrm{L}$ of TCHQ for 0.5 or $1 \mathrm{~h}$, we observed a dose-dependent decrease in the number of transformations, a dose-dependent increase in the number of mutations and a dose-dependent increase in mutation frequency (Table 2). Additionally, treatment with TCHQ for $1 \mathrm{~h}$ resulted in a lower number of transformations and higher number of mutations and higher mutation frequency than treatment of TCHQ for $0.5 \mathrm{~h}$ (Table 2). Therefore, we chose $50 \mu \mathrm{mol} / \mathrm{L} \mathrm{TCHQ}$ with $1 \mathrm{~h}$ incubation time as the standard conditions for subsequent studies to determine the nature, sites, and sequence specificity of TCHQ-induced DNA mutations. After replication in A549 cells, the pSP189 plasmid DNA had a calculated mutation frequency of $39.06 \times 10^{-4}$, showing a 19 -fold increase from the $2.04 \times 10^{-4}$ mutation frequency seen in the controls. Additionally, we noticed that simultaneous addition of DFO caused significantly lower mutation frequency than treatment with TCHQ alone. These DFO-treated cells demonstrated a mutation frequency of $6.81 \times 10^{-4}$.

\subsection{The spectrum of TCHQ-treated pSP189 plasmid mutations}

In our study, the control groups had a total of six mutations in the supF tRNA gene in the six sequenced colonies (Fig. 5A). Four of the mutations were different from the TCHQ-treated group and occurred at nucleotides 122, 132, 144 and 150, respectively. Most of the mutations occurred at $\mathrm{G}: \mathrm{C}$ base pairs, and these mutations were also found among TCHQ-induced mutations.

Of all the TCHQ-induced mutations, single base substitutions accounted for $85.36 \%$ of the mutations (Table 3 ). Other types of mutations included single base insertions (9.76\%) and large fragment deletions (4.88\%). Most point mutations occurred at $\mathrm{G}: \mathrm{C}$ base pairs, and $\mathrm{G}: \mathrm{C} \rightarrow \mathrm{C}: \mathrm{G}$ or $\mathrm{G}: \mathrm{C} \rightarrow \mathrm{A}: \mathrm{T}$ mutations were predominant ( $34.3 \%$ and $37.1 \%$ of the base pair substitutions, respectively), followed by G:C $\rightarrow$ T:A and A:T $\rightarrow$ C:G $(11.43 \%$ and $14.29 \%$, respectively). The ratio of transversions to transitions was 1.69:1 (Table 3, Fig. $5 \mathrm{~A}$ and $\mathrm{B}$ ). Of the base substitutions, there was a significant decrease in $\mathrm{G}: \mathrm{C} \rightarrow \mathrm{T}: \mathrm{A}$ and $\mathrm{A}: \mathrm{T} \rightarrow \mathrm{G}: \mathrm{C}$ mutations when treated with TCHQ alone compared with the background level. The proportion of these mutations decreased considerably from 40 to $11.4 \%$ and $20 \%$ to zero, respectively (Fig. 5 c). In contrast, $G: C \rightarrow C: G$ mutations increased markedly with TCHQ treatment. Additionally, A:T $\rightarrow$ C:G and $\mathrm{A}: \mathrm{T} \rightarrow \mathrm{T}: \mathrm{A}$ transversions, which were not evident in control plasmid, were apparent after TCHQ exposure, and they contributed $14.3 \%$ and $2.9 \%$ of the total induced substitutions (Fig. $5 \mathrm{c}$ ). However, when DFO was added simultaneously with TCHQ, the mutation frequency was significantly decreased, with prominent decreases in $\mathrm{G}: \mathrm{C} \rightarrow \mathrm{C}: \mathrm{G}$ and $\mathrm{G}: \mathrm{C} \rightarrow \mathrm{A}: \mathrm{T}$ mutations(Table 3, Fig. 5B).

All mutations occurred at positions 99, 105, 111, 113, 123, 129, 132, 141, 155 and 169, 108-109, 144-145, 168-169 and 173-174. Large fragment deletions were found at base pairs $96-115$ and 114-148. Seventy-five percent of the TCHQ-induced base insertions occurred at the $5^{\prime}$-TCC- $3^{\prime}$ sequence (Table 3; Fig. 5). Approximately $85.71 \%$ of all the mutations in the supF gene in pSP189 plasmids replicated in A549 cells occurred at five sites. The 129,141 , and 155 positions comprised $62.86 \%$, and nucleotides 105 and 113 were also highly represented. The first three positions were considered mutation "hotspots" in our study, and they are 


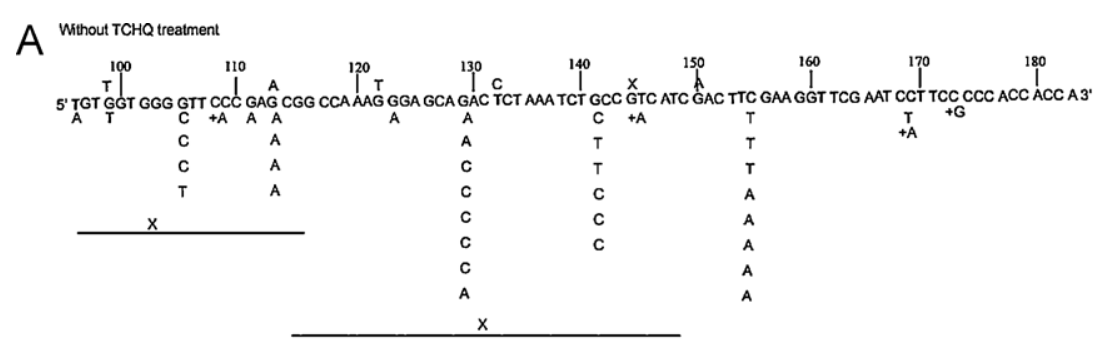

With TCHQ treatment

B
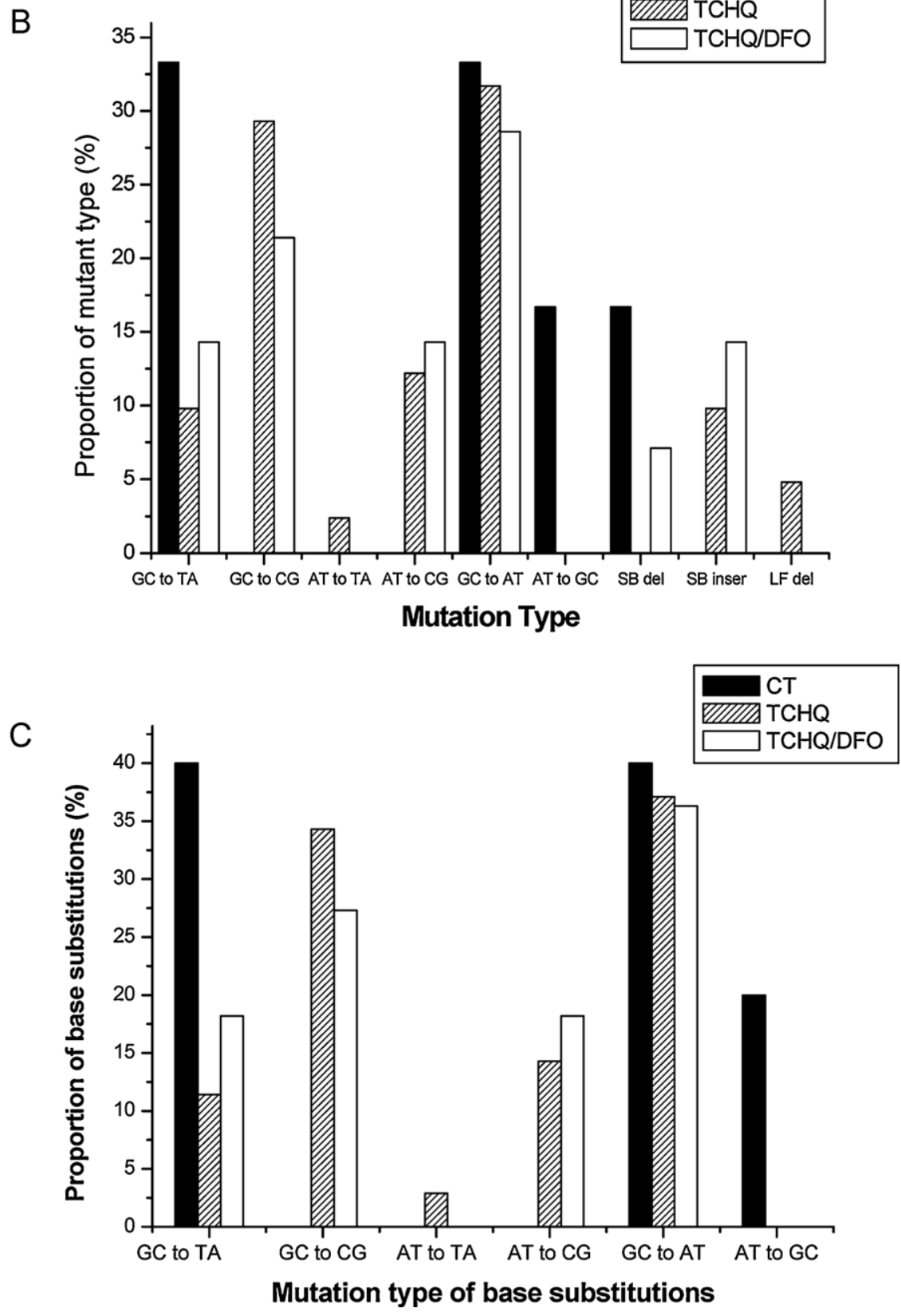

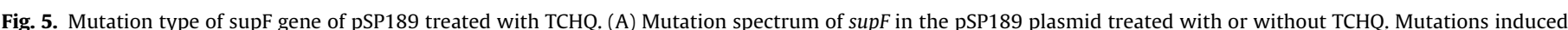

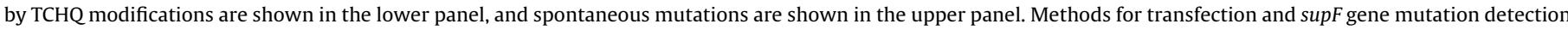

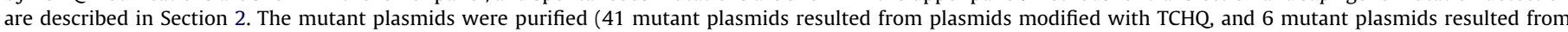

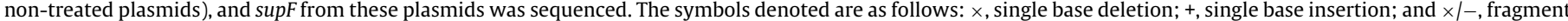

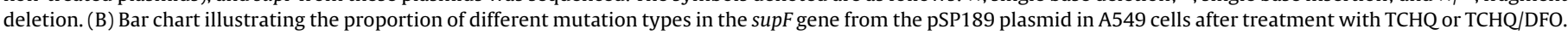

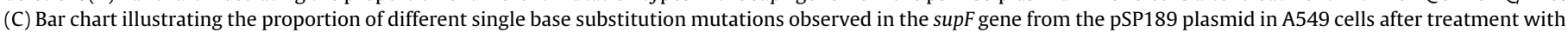
TCHQ or TCHQ/DFO. 
Table 2

Transformation and mutation frequency in pSP189 plasmids exposed to TCHQ in A549 human lung carcinoma cells.

\begin{tabular}{|c|c|c|c|c|}
\hline TCHQ $(\mu \mathrm{mol} / \mathrm{L})$ & Incubation time $(\mathrm{h})$ & Number of transformants & Number of mutants & Mutation frequency $\left(\times 10^{-4}\right)$ \\
\hline 0 & 0.5 & 29,987 & 3 & 1.00 \\
\hline Vehicle & 1 & 29,324 & 6 & 2.04 \\
\hline 10 & 0.5 & 23,013 & 12 & 5.21 \\
\hline 25 & 0.5 & 18,054 & 12 & 6.65 \\
\hline 50 & 0.5 & 14,305 & 20 & 13.98 \\
\hline 10 & 1 & 20,008 & 13 & 6.50 \\
\hline 25 & 1 & 15,834 & 27 & 17.05 \\
\hline 50 & 1 & 10,498 & 41 & 39.06 \\
\hline TCHQ/DFO & 1 & 20,569 & 14 & 6.81 \\
\hline DFO only & 1 & 29,768 & 5 & 1.68 \\
\hline
\end{tabular}

clustered within a small region of the supF gene. Thus, TCHQinduced mutations are sequence-specific, not random.

\section{Discussion}

Tetrachlorohydroquinone (TCHQ) has been identified as the main DNA damaging metabolite in the widely used and ubiquitously found pentachlorophenol (PCP). TCHQ autoxidizes in two one-electron steps: the first is to its tetrachlorosemiquinone (TCSQ) radical and the second is to its quinine. The resulting free electrons reduce oxygen to ROS. It has been reported that both ROS and tetrachlorosemiquinone radicals are produced during autoxidation of TCHQ and the pronounced genotoxic properties of TCHQ may not be caused by hydroxyl radicals but instead by the tetrachlorosemiquinone radicals [24]. Comet assays, also called single cell gel electrophoresis, are frequently used to evaluate genotoxicity of test substances [28]. Using a comet assay, we determined the extent of DNA damage in Vero cells treated with TCHQ (Table 1 and Fig. 2). In this study, TCHQ-induced DNA damage, measured by comet assays and by SSB detection, was not completely inhibited by DMSO. However, cells were significantly protected by DFO, a scavenger of TCSQ radicals. This verified the influence of TCSQ radicals in DNA damage. Therefore, it is possible that TCSQ radicals may play a more important role in initiating genotoxic responses. Previous reports have indicated that over-expression of Bcl-2 in NIH3T3 cells dramatically decreases the percentage of apoptotic cells only partially inhibits genotoxicity induced by TCHQ [29]. All these data imply that TCHQ-induced genotoxicity is mainly caused by TCSQ radicals.

Additionally, the mechanisms of TCHQ toxicity may involve binding of TCHQ to critical thiol groups in proteins or to specific nucleotides in the genome. Gene mutations result from an accumulation of errors during DNA replication and repair [30]. The pSP189 shuttle vector plasmid provides an excellent platform to detect DNA damage caused by many physical or chemical mutagens in mammalian cells [31-33]. The supF assay has been previously

Table 3

Types of mutations in the supF gene in TCHQ-treated Psp189 plasmids replicated in A549 human lung carcinoma cells.

\begin{tabular}{llcl}
\hline Types of mutations & Control & TCHQ & TCHQ/DFO \\
\hline $\begin{array}{l}\text { Single base substitutions } \\
\text { Transversions }\end{array}$ & $5(83.3 \%)$ & $35(85.36 \%)$ & $11(78.57 \%)$ \\
$\quad$ GC to TA & 2 & 4 & 2 \\
GC to CG & 0 & 12 & 3 \\
AT to TA & 0 & 1 & 0 \\
AT to CG & 0 & 5 & 2 \\
Transitions & & & \\
GC to AT & 2 & 13 & 4 \\
AT to GC & 1 & 0 & 0 \\
Single base deletions & $1(16.7 \%)$ & 0 & $1(7.14 \%)$ \\
Single base insertions & 0 & $4(9.76 \%)$ & $2(14.29 \%)$ \\
Large fragments deletions & 0 & $2(4.88 \%)$ & 0 \\
\hline
\end{tabular}

used to demonstrate the mutagenicity of a wide variety of genotoxic agents in mammalian cells, including bulky adducts, small alkyl lesions such as cyclic etheno adducts, $\mathrm{O}^{6}$-methyl- and $\mathrm{O}^{6}$ ethyl-2'-deoxyguanosine, and oxidative DNA damage [21,34-36]. A distinct advantage of the supF methodology is the ability to determine plasmid adduct profiles and accurately quantify the degree of damage, which allows correlation with any observed mutagenic effects. While it is well known that TCHQ is a mutagen and potential carcinogen that causes DNA damage, detected by us in this study using single cell gel electrophoresis assay (SCGE) as well, the nature of this DNA damage, the sites of mutations, and the characteristics of TCHQ-induced DNA mutations in mammalian cells remain to be fully characterized, this study investigated the mutagenicity of TCHQ using the supF shuttle vector system. Our results indicated that mutations and DNA damage caused by TCHQ are dose- and time-dependent, consistent with previous reports showing that TCHQ is a potent mutagen $[5-8,10,11]$. We also found that most predominant mutations in supF are point mutations. DFO, a specific scavenger of TCSQ radicals, markedly inhibited mutations induced by TCHQ suggesting that TCSQ-induced oxidative damage is the primary cause of mutation.

It is increasingly evident that various types of oxidative DNA damage can be derived from ROS interactions with DNA. Previous studies have shown that TCHQ-induced formation of direct DNA adducts in a concentration and time-dependent manner [37]. In parallel, an increased number of AP sites and 8-OH-dG were detected in cells treated with TCHQ [37]. The levels of AP sites and 8-OH-dG were estimated to be approximately two orders of magnitude greater than those of direct DNA adducts. Additionally, the ratio of the net increase of 8-OH-dG to AP sites in HeLa S3 cells induced by TCHQ is estimated to be $1: 6$ [37]. TCHQ could also induce the formation of 8-OH-dG in V79 cells and in mice $[12,15]$.

Characteristics of DNA polymerases, type of DNA damage and the cell background can affect the type, sequence context and hotspot positions of mutations. Of the base substitutions induced by TCHQ treatment, the majority were $\mathrm{G}: \mathrm{C} \rightarrow \mathrm{C}: \mathrm{G}$ transversions and $\mathrm{G}: \mathrm{C} \rightarrow \mathrm{A}: \mathrm{T}$ transitions (12/35 and 13/35). On the basis of the studies demonstrating strong electrophilic abilities of TCSQ and TCBQ [38], we hypothesize that DNA alkylation and DNA adducts are formed. If $\mathrm{G}$ is alkylated, there are two possible outcomes. One outcome is to hydrolyze the nucleotide to form AP sites. In this case, any base can participate in forming a variety of base substitutions such as $\mathrm{G}: \mathrm{C}$ to $\mathrm{A}: \mathrm{T}$ transitions and $\mathrm{G}: \mathrm{C}$ to $\mathrm{C}: \mathrm{G}$ or $\mathrm{G}: \mathrm{C}$ to $\mathrm{T}: \mathrm{A}$ transversions. The other outcome is to ionize the alkylated $G$, which changes the former ketonic type to an unstable enol type. This type readily leads to mismatching errors with $\mathrm{T}$, resulting in formation of $\mathrm{G}: \mathrm{C}$ to $\mathrm{A}: \mathrm{T}$ transitions. Of the base substitutions induced by TCHQ treatment, another major cause of the G:C to T:A and A:T to C:G mutations (a total of 9 mutation in 35 base substitution) may be the result of forming 8-OH-dG. Previous studies demonstrated that if DNA polymerase I or II does not excise the A on the opposite side of an 8-OH-dG, a G:C to T:A transversion could be formed. However, if 
8-OH-dG was used as a substrate in DNA synthesis, it can match with either $\mathrm{dG}$ or $\mathrm{dA}$, resulting in an AT to CG transversion.

It remains unclear why $\mathrm{G}: \mathrm{C}$ base pairs are the preferred target sites for base pair substitutions and why specific sequences were hotspots for TCHQ-induced mutations. It has been known that DNA methylation and demethylation, occurring on position 5 of cytosine bases, play a key role in regulation of gene expression and genome reprogramming. Moreover, 5-methylcytosine is the main cause of the hotspots of DNA genome. However, from the detection of TCHQ-DNA adducts, we hypothesize that TCHQ may react with plasmid DNA to form TCHQ-DNA adducts, and G:C base pairs are the preferential source for generating these TCHQ-DNA adducts. TCHQ-DNA adducts may pair with T, G or protonated adenine, in addition to $C[25,26,31]$. However, the levels of AP sites and $8-\mathrm{OH}-\mathrm{dG}$ were estimated to be approximately two orders of magnitude greater than the previously reported levels from direct DNA adducts [37]. However, we cannot exclude the possibility that the relative levels of DNA lesions could be underestimated because the ${ }^{32} \mathrm{P}$-post-labeling method may not fully recover direct adducts induced by TCHQ. Additionally, formation of AP sites may be one of the major types of oxidative DNA damage induced by TCHQ in intact cells.

Because of the critical roles of DNA mutations in the initiation step during carcinogenesis, our results reveal that TCHQ causes increases in genotoxicity and gene mutation in mammalian cells, thus providing new evidence for the mutagenic effect of PCP on cancer development. Further studies should lead to better understanding of this preference to facilitate development of improved procedures and establish monitoring systems to detect TCHQrelated toxic events and health risks.

\section{Conflict of interest}

The authors declare that there are no conflicts of interest.

\section{Acknowledgements}

The authors express their sincere thanks to Dr. Paul Tchounuou and three anonymous reviewers for their useful comments and suggestions on our manuscript.

We thank Dr. Michael M. Seidman from the National Institutes of Health, USA, for providing the E. coli MBM7070 strain and the pSP189 shuttle vector plasmid.

This work was supported by the National Basic Research Program (973) of China (Nos. 2008CB418102 and 2009CB421605) and the National Natural Science Foundation of China (Nos. 20890112 and 21077127).

\section{References}

[1] J.P. Seiler, Pentachlorophenol, Mutat. Res. 257 (1991) 27-47.

[2] I. Witte, B.Z. Zhu, A. Lueken, D. Magnani, H. Stossberg, M. Chevion, Protection by desferrioxamine and other hydroxamic acids against tetrachlorohydroquinone-induced cyto- and genotoxicity in human fibroblasts, Free Radic. Biol. Med. 28 (2000) 693-700.

[3] Y.J. Wang, M.C. Yang, M.H. Pan, Dihydrolipoic acid inhibits tetrachlorohydroquinone-induced tumor promotion through prevention of oxidative damage, Food Chem. Toxicol. 46 (2008) 3739-3748.

[4] U.G. Ahlborg, K. Larsson, T. Thunberg, Metabolism of pentachlorophenol in vivo and in vitro, Arch. Toxicol. 40 (1978) 45-53.

[5] B. van Ommen, A. Adang, F. Muller, P.J. van Bladeren, The microsomal metabolism of pentachlorophenol and its covalent binding to protein and DNA, Chem. Biol. Interact. 60 (1986) 1-11.

[6] W.C. Chang, J.H. Jeng, C.C. Shieh, Y.C. Tsai, Y.S. Ho, H.R. Guo, H.I. Liu, C.C. Lee, S.Y. Ho, Y.J. Wang, Skin tumor-promoting potential and systemic effects of pentachlorophenol and its major metabolite tetrachlorohydroquinone in CD-1 Mice, Mol. Carcinog. 36 (2003) 161-170.

[7] C.P. Carstens, J.K. Blum, I. Witte, The role of hydroxyl radicals in tetrachlorohydroquinone induced DNA strand break formation in PM2 DNA and human fibroblasts, Chem. Biol. Interact. 74 (1990) 305-314.
[8] B.Z. Zhu, G.Q. Shan, Potential mechanism for pentachlorophenol-induced carcinogenicity: a novel mechanism for metal-independent production of hydroxyl radicals, Chem. Res. Toxicol. 22 (2009) 969-977.

[9] I. Witte, U. Juhl, W. Butte, DNA-damaging properties and cytotoxicity in human fibroblasts of tetrachlorohydroquinone, a pentachlorophenol metabolite, Mutat. Res. 145 (1985) 71-75.

[10] M. Dahlhaus, E. Almstadt, P. Henschke, S. Luttgert, K.E. Appel, Oxidative DNA lesions in V79 cells mediated by pentachlorophenol metabolites, Arch. Toxicol. 70 (1996) 457-460.

[11] W. Ehrlich, The effect of pentachlorophenol and its metabolite tetrachlorohydroquinone on cell growth and the induction of DNA damage in Chinese hamster ovary cells, Mutat. Res. 244 (1990) 299-302.

[12] M. Dahlhaus, E. Almstadt, K.E. Appel, The pentachlorophenol metabolite tetrachloro-p-hydroquinone induces the formation of 8-hydroxy-2deoxyguanosine in liver DNA of male B6C3F1 mice, Toxicol. Lett. 74 (1994) 265-274.

[13] Y.J. Wang, Y.S. Ho, S.W. Chu, H.J. Lien, T.H. Liu, J.K. Lin, Induction of glutathione depletion, p53 protein accumulation and cellular transformation by tetrachlorohydroquinone, a toxic metabolite of pentachlorophenol, Chem. Biol. Interact. 105 (1997) 1-16.

[14] K. Jansson, V. Jansson, Induction of micronuclei in V79 Chinese hamster cells by tetrachlorohydroquinone, a metabolite of pentachlorophenol, Mutat. Res. 279 (1992) 205-208.

[15] M. Dahlhaus, E. Almstadt, P. Henschke, S. Luttgert, K.E. Appel, Induction of 8hydroxy-2-deoxyguanosine and single-strand breaks in DNA of V79 cells by tetrachloro-p-hydroquinone, Mutat. Res. 329 (1995) 29-36.

[16] C.N. Parris, M.M. Seidman, A signature element distinguishes sibling and independent mutations in a shuttle vector plasmid, Gene 117 (1992) 1-5.

[17] H.C. Chiang, T.C. Tsou, Arsenite enhances the benzo[a]pyrene diol epoxide (BPDE)-induced mutagenesis with no marked effect on repair of BPDE-DNA adducts in human lung cells, Toxicol. In Vitro 23 (2009) 897-905.

[18] W. Hu, Z. Feng, M.S. Tang, Nickel (II) enhances benzo[a]pyrene diol epoxideinduced mutagenesis through inhibition of nucleotide excision repair in human cells: a possible mechanism for nickel (II)-induced carcinogenesis, Carcinogenesis 25 (2004) 455-462.

[19] T.C. Tsou, F.Y. Tsai, M.C. Wu, L.W. Chang, The protective role of NF-kappaB and AP-1 in arsenite-induced apoptosis in aortic endothelial cells, Toxicol. Appl. Pharmacol. 191 (2003) 177-187.

[20] J.L. Yang, V.M. Maher, J.J. McCormick, Kinds of mutations formed when a shuttle vector containing adducts of $(+/-)-7$ beta, 8 alpha-dihydroxy-9 alpha, 10 alpha-epoxy-7,8,9, 10-tetrahydrobenzo[a]pyrene replicates in human cells Proc. Natl. Acad. Sci. U.S.A. 84 (1987) 3787-3791.

[21] E.M. Tompkins, K.I. McLuckie, D.J. Jones, P.B. Farmer, K. Brown, Mutagenicity of DNA adducts derived from ethylene oxide exposure in the pSP189 shuttle vector replicated in human Ad293 cells, Mutat. Res. 678 (2009) 129-137.

[22] B.Z. Zhu, B. Kalyanaraman, G.B. Jiang, Molecular mechanism for metalindependent production of hydroxyl radicals by hydrogen peroxide and halogenated quinones, Proc. Natl. Acad. Sci. U.S.A. 104 (2007) $17575-17578$

[23] B.Z. Zhu, H.T. Zhao, B. Kalyanaraman, J. Liu, G.Q. Shan, Y.G. Du, B. Frei, Mechanism of metal-independent decomposition of organic hydroperoxides and formation of alkoxyl radicals by halogenated quinones, Proc. Natl. Acad. Sci. U.S.A. 104 (2007) 3698-3702.

[24] M. Purschke, H. Jacobi, I. Witte, Differences in genotoxicity of $\mathrm{H}(2) \mathrm{O}(2)$ and tetrachlorohydroquinone in human fibroblasts, Mutat. Res. 513 (2002) 159-167.

[25] T. Nakano, K. Okaichi, K. Harada, H. Matsumoto, R. Kimura, K. Yamamoto, S. Akasaka, T. Ohnishi, Mutations of a shuttle vector plasmid, pZ189, in Escherichia coli induced by boron neutron captured beam (BNCB) containing alpha-particles, Mutat. Res. 336 (1995) 153-159.

[26] M.J. Juedes, G.N. Wogan, Peroxynitrite-induced mutation spectra of pSP189 following replication in bacteria and in human cells, Mutat. Res. 349 (1996) 51-61.

[27] Q. Chen, Y. Chen, Y. Qi, L. Hao, S. Tang, X. Xiao, Characterization of carbadoxinduced mutagenesis using a shuttle vector pSP189 in mammalian cells, Mutat. Res. 638 (2008) 11-16.

[28] E.M. de Oliveira, M.F. Suzuki, P.A. do Nascimento, M.A. da Silva, K. Okazaki, Evaluation of the effect of $90 \mathrm{Sr}$ beta-radiation on human blood cells by chromosome aberration and single cell gel electrophoresis (comet assay) analysis, Mutat. Res. 476 (2001) 109-121.

[29] Y.P. Lin, B.Z. Zhu, M.C. Yang, B. Frei, M.H. Pan, J.K. Lin, Y.J. Wang, Bcl-2 overexpression inhibits tetrachlorohydroquinone-induced apoptosis in NIH3T3 cells: a possible mechanism for tumor promotion, Mol. Carcinog. 40 (2004) 24-33.

[30] Z. Wang, DNA damage-induced mutagenesis: a novel target for cancer prevention, Mol. Interv. 1 (2001) 269-281.

[31] K.A. Canella, M.M. Seidman, Mutation spectra in supF: approaches to elucidating sequence context effects, Mutat. Res. 450 (2000) 61-73.

[32] C. Czerny, E. Eder, T.M. Runger, Genotoxicity and mutagenicity of the alpha, beta-unsaturated carbonyl compound crotonaldehyde (butenal) on a plasmid shuttle vector, Mutat. Res. 407 (1998) 125-134.

[33] M. Gaskell, K.I. McLuckie, P.B. Farmer, Comparison of the mutagenic activity of the benzene metabolites, hydroquinone and para-benzoquinone in the supF forward mutation assay: a role for minor DNA adducts formed from hydroquinone in benzene mutagenicity, Mutat. Res. 554 (2004) 387-398. 
[34] D.C. Upton, X. Wang, P. Blans, F.W. Perrino, J.C. Fishbein, S.A. Akman, Mutagenesis by exocyclic alkylamino purine adducts in Escherichia coli, Mutat. Res. 599 (2006) 1-10.

[35] D.H. Lee, G.P. Pfeifer, Translesion synthesis of 7, 8-dihydro-8-oxo-2' deoxyguanosine by DNA polymerase eta in vivo, Mutat. Res. 641 (2008) 19-26.

[36] K.I. McLuckie, J.H. Lamb, J.K. Sandhu, H.L. Pearson, K. Brown, P.B. Farmer, D.J. Jones, Development of a novel site-specific mutagenesis assay using MALDI-ToF MS (SSMA-MS), Nucleic Acids Res. 34 (2006) e150.
[37] P.H. Lin, J. Nakamura, S. Yamaguchi, D.K. La, P.B. Upton, J.A. Swenberg, Induction of direct adducts, apurinic/apyrimidinic sites and oxidized bases in nuclear DNA of human HeLa S3 tumor cells by tetrachlorohydroquinone, Carcinogenesis 22 (2001) 635-639.

[38] J.-G.Z Ben-Zhan Zhu, Rui-Mei Fan, Mao Li, Chapter one-metal-independent pathways of chlorinated phenol/quinone toxicity, Adv. Mol. Toxicol. 5 (2011) $1-43$. 